\title{
Questões para o planejamento na Região Metropolitana de Curitiba ${ }^{\dagger}$
}

\author{
Demian Castro* \\ Maria Inês Cavichiolli** \\ Guilherme Augusto Almeida**
}

RESUMO - A Região Metropolitana de Curitiba carece de uma instância de planejamento com poder fiscal em condições de superar os gargalos de financiamento do Governo do Estado. Ao mesmo tempo, os municípios que integram o espaço metropolitano demonstram enormes assimetrias nas suas finanças públicas; uma grande maioria mal consegue gerar recursos para atender as necessidades mais elementares da sua população, reforçando o enorme poder polarizador da capital. Esta realidade, talvez menos dramática do que em outras regiões do país, obriga-nos a pensar nas peças que faltam na Federação no sentido de tornar mais efetivo o processo de planejamento.

\section{INTRODUÇÃO}

Neste texto, dividido em quatro seções, incluindo esta introdução, e uma pequena conclusão, iremos abordar problemas e desafios que o espaço metropolitano suscita para a sociedade e para os governos que o ocupam, a partir de uma primeira visão das assimetrias fiscais e da inexistência de uma instância federativa metropolitana, principalmente coordenadora e com poder de gasto. Na segunda seção, abordamos a Região Metropolitana de Curitiba como um espaço precariamente articulado por processos de planejamento. A título de provocação, levantamos alguns pontos da questão social que, para além da existência de indicadores sociais bastante completos, permeiam o espaço metropolitano e rebatem nas políticas públicas. $\mathrm{Na}$ terceira seção, fazemos uma síntese dos principais aspectos que caracterizam o padrão de financiamento dos governos municipais no Brasil. Na última seção, tentamos mostrar as assimetrias fiscais entre os municípios que compõem a Região Metropolitana de Curitiba. Na conclusão, reforça-se a necessidade de refletir a respeito da importância estratégica de dotar a Federação brasileira de esferas competentes para intervir nos espaços metropolitanos. Os autores pretendem voltar com alguma frequência à discussão dos múltiplos significados que assume a metrópole no atual estágio do desenvolvimento capitalista no Brasil, e espera-se que ao longo do tempo os textos possam ganhar maior rigor analítico.

\footnotetext{
*Doutor em economia pela Universidade Estadual de Campinas. É professor do Departamento de Economia da Universidade Federal do Paraná. Endereço eletrônico: demian@ufpr.br.

** Coordenadora de Projetos e Informações da Secretaria Municipal de Educação / Prefeitura Municipal de Curitiba. Endereço eletrônico: mcavichiolli@sme.curitiba.pr.gov.br.

*** Acadêmico do curso de Ciências Econômicas da Universidade Federal do Paraná.
} 


\section{A REGIÃO METROPOLITANA DE CURITIBA: UM CONCEITO A SER CONS- TRUÍDO}

Um observador que percorra os 26 municípios que fazem parte da Região Metropolitana de Curitiba (RMC), em algum momento irá se perguntar sobre a pertinência de caracterizar tal espaço como uma região, tamanha a heterogeneidade, desigualdade e descontinuidade espacial constatadas. Custa visualizar esse espaço como um grande espaço urbano a abrigar uma metrópole com as suas partes conectadas, embora seja possível imaginar que o implacável avanço do capital imobiliário, a partir do município polarizador de Curitiba, em algum momento próximo poderá “unificar” o mercado de terras. A percepção de uma metrópole com muitos elos frágeis, em muitos aspectos inorgânica, é reforçada pela constatação de que, para além do caráter legal da RMC, inexistem instâncias públicas metropolitanas que executem políticas metropolitanas profundas, nem os municípios dão sinais de que desejam construir um espaço para executar políticas de modo cooperativo.

A falta de planejamento focado em relações intergovernamentais horizontais constitui uma das grandes mazelas da Federação brasileira. As regiões metropolitanas não gozam de personalidade jurídica própria equivalente às esferas federativas consagradas pela Constituição de 1988. A falta de capacidade efetiva para planejar vale também para os estados da Federação, com baixa capacidade de investimento em infraestrutura e com ações frágeis ou assintomáticas em matéria metropolitana. Tampouco observam-se ações cooperativas entre estados, embora de vez em quando estes se associem nas reivindicações relativas à dívida pública estadual e sua rolagem possível.

No caso do estado do Paraná, a Coordenação da Região Metropolitana de Curitiba (COMEC), originariamente criada para coordenar as ações públicas de âmbito metropolitano, numa época em que o regime autoritário estabelecia verticalmente políticas de desenvolvimento urbano, não possui capacidade financeira, sofre os males do orçamento público estadual no que se refere a investimentos e, de maneira geral, a perda de importância relativa dos estados no cenário federativo brasileiro. É necessário pensar se as ações nos espaços metropolitanos não deveriam emergir de um arranjo federativo explícito. Para além da existência de planos integrados com dificuldades de sair do campo virtual, pode-se apontar apenas uma Rede Integrada de Transporte (RIT) envolvendo 14 municípios da RMC.

Para agravar as possibilidades de construção de um conceito de cidade-metrópole, é importante apontar a falta de entendimento sobre os contornos da questão social inserida no presumível espaço metropolitano. Pouco sabemos sobre a cidade que habitamos, muito menos das outras cidades do entorno. Quais as conexões sociais e espaciais da violência e dos furtos? 
O que os pichadores estão escrevendo e por quê? Quem são os jovens estereotipados em diversas tribos da periferia? Que pensam (ou escutam nos tocadores de música) os milhares que estudam à noite enquanto são transportados em longas jornadas pelo sistema de transporte? Que tipo de antídotos culturais, econômicos e políticos são necessários contra o avanço do crack? Como vivem os idosos e que suporte familiar recebem? Que perfil possuem os trabalhadores da construção civil que são "importados" pelas grandes construtoras nacionais que atuam em Curitiba? O que é estar inseguro ou ter sempre medo em cada um desses 26 municípios? Qual o futuro dos municípios dormitório? Para além do IDH, as políticas públicas conseguem desfazer o mal-estar na sociedade e na cultura? A fragmentação social é irremediável? Como, nestas circunstâncias, se desenvolve um conceito de região metropolitana? Há de fato uma metrópole ou esta é apenas uma representação do que virá? São algumas das perguntas a serem feitas e que bem podem comandar um programa interdisciplinar de pesquisa.

Independentemente das respostas a estas (e tantas outras) perguntas, pode-se resgatar a ideia de que a RMC é um espaço deliberadamente construído para o planejamento do processo de expansão urbana. Falta, no entanto, no campo federativo, encontrar/construir o ator que dará sentido e efetividade ao planejamento que o conceito pressupõe. No atual cenário das finanças públicas estaduais é duvidoso acreditar que os governos estaduais possam vir a desempenhar esta função.

\section{CONSIDERAÇÕES SOBRE O PADRÃO DE FINANCIAMENTO PÚBLICO MU- NICIPAL NO BRASIL}

O município é o epicentro das demandas sociais; o processo de descentralização assume, implicitamente ou explicitamente, que os níveis inferiores de governo apresentam melhores condições, pela proximidade espacial, de responder às necessidades das comunidades; por sua vez, estas podem identificar e pressionar melhor os atores/gestores responsáveis pelo planejamento e execução das ações públicas. Nos últimos vinte anos o fantástico processo de descentralização fiscal do país estabeleceu-se, principalmente, entre o Governo Federal e os governos municipais; os governos estaduais perderam poder e capacidade fiscal, limitada, entre outras coisas, pelos encargos das dívidas.

Apesar de dotados de autonomia política, os municípios brasileiros são caracterizados por elevada dependência financeira das transferências efetuadas pelos níveis mais elevados de governo: os estados e o Governo Federal. As receitas tributárias dos municípios representam menos de vinte por cento da carga tributária bruta brasileira; de modo geral, é possível apontar que os dois impostos municipais, o ISS e o IPTU, estão muito aquém dos encargos, principal- 
mente em políticas sociais, que os municípios devem assumir. Ao mesmo tempo, as transferências que os municípios recebem longe estão de produzir um efeito equalizador do poder fiscal; basicamente, endossam as assimetrias existentes. Não deve acreditar-se num poder "heroico" das transferências públicas, quando a economia trabalha com altos graus de concentração e dá poucos sinais de que os mercados concorrenciais podem prosperar. É importante questionar, para além dos fluxos transferidos, se as lacunas federativas observadas, no campo do planejamento metropolitano, não deveriam levar a focar a necessidade de constituir fundos públicos específicos para políticas públicas desse escopo. Infelizmente, a experiência democrática brasileira pouco realizou em matéria de planejamento urbano e o processo histórico ainda nos joga a referência das políticas de desenvolvimento urbano do período autoritário.

Por outro lado, dadas as enormes diferenças de bases econômicas e a concentração característica do nosso padrão de desenvolvimento, é muito acentuada a dispersão da capacidade fiscal entre os municípios. Essa diferença é constatada não apenas entre as regiões do país, mas, com muita frequência, entre municípios das regiões metropolitanas. E, como poderá constatar-se, na RMC não é diferente.

De modo complementar, o endividamento dos níveis inferiores de governo tem sido controlado de modo bastante eficaz por uma legislação rigorosa, como por exemplo, a lei de Responsabilidade Fiscal e, também, pelas autoridades federais, o que certamente contribui para o controle e disciplina fiscal. Porém, para uma grande maioria dos municípios, esses controles e a baixa capacidade de endividamento em razão das receitas próprias acabam restringindo seu acesso ao sistema de crédito, crucial para realização de obras e investimentos. Da mesma forma que para os indivíduos, o acesso restrito ao crédito para os governos municipais acaba reforçando o ciclo da desigualdade e falta de oportunidades.

\section{POPULAÇÃO E FINANÇAS PÚBLICAS DOS MUNICÍPIOS DA REGIÃO ME- TROPOLITANA DE CURITIBA}

A RMC foi criada em 1973 com 14 municípios e, no começo da década de noventa, num ambiente de expansão do número de municípios, mais 12 foram desmembrados e incorporados à região. De modo similar ao que aconteceu no resto do país, a criação de municípios aglutinou interesses econômicos e políticos, embora, ao longo do tempo, muitos continuem demonstrando enorme vocação para a falta de autonomia.

A divulgação de dados demográficos é crucial para receber ou deixar de receber recursos de transferências federais. Quando projeções de censos confirmam o aumento populacional, surgem vozes e projetos que se alçam em prol do aumento de membros das Câmaras de 
Vereadores. Estes fenômenos são marcados pela falta de projetos de desenvolvimento.

Vale indicar que a RMC é uma das que apresentam maior extensão territorial do país, fazendo fronteira com os estados de São Paulo e Santa Catarina. Sua condição social em termos de IDH, em oitavo lugar (IDH-M 2003) nas regiões metropolitanas, é de fazer inveja. No entanto, a desigualdade é marcante como em todo o país, da mesma forma que a segregação espacial da população, empurrada para as áreas mais longínquas e de menor valor imobiliário. Não é novidade que esse padrão se reproduz, também, no interior de cada município. A RMC apresentou, no censo demográfico de 2010, 3.168.980 habitantes (a oitava do país), sendo 252.332 população rural e 2.916 .648 população urbana. A capital, Curitiba, apresentou população de 1.746.896 habitantes, sendo esta 100\% urbana. Junto com o município de Curitiba, outros seis apresentaram população acima dos cem mil habitantes: Almirante Tamandaré, Araucária, Campo Largo, Colombo, Pinhais e São José dos Pinhais. É nesse conjunto que se concentra a parte mais relevante do PIB da RMC (menos Almirante Tamandaré e Colombo) e, também, a capacidade de arrecadação e de gasto público municipal.

Sob qualquer ótica (população, PIB, receitas e despesas municipais), Curitiba apresenta um papel de destaque absoluto. O município de Araucária, uma espécie de Qatar pobre, apresenta números de destaque pela existência de uma refinaria da Petrobras, que se contrapõe, em termos de geração de valor, à pobreza da grande maioria da população de 119.207 habitantes. Ao observar os números das tabelas 1 e 2, constata-se porque Curitiba, de fato, exerce um papel de núcleo polarizador e entende-se que alguns de seus serviços essenciais, como saúde, acabam atendendo ao conjunto da população metropolitana. Na prática, a gestão pública municipal em Curitiba dá conta de algumas das demandas da população de outros municípios, mas, a inexistência de um órgão, com capacidade política e financeira, planejador e executor de políticas públicas, favorece o avanço implacável dos interesses econômicos, financeiros e imobiliários sobre o universo do bem-estar social.

A concentração das receitas e despesas é patente em termos absolutos, porém, em termos per capita (tabelas 1 e 2), a distribuição é menos desigual, desde que excluindo Curitiba, Araucária e São José dos Pinhais. De qualquer forma, verifica-se importante dispersão de dados. Pode constatar-se que Almirante Tamandaré, com 103.245 habitantes, apresenta receitas e despesas municipais absurdamente baixas quando comparadas a de municípios com população equivalente. Junto com Colombo, este território parece abrigar um exército de trabalhadores formais e informais de baixa qualificação que, às vezes, tem a sorte de sobreviver a partir de empregos em Curitiba. É possível constatar um círculo virtuoso envolvendo PIB (indústrias e serviços) e capacidade de arrecadação e gastos, embora isto nem sempre se traduza em bem- 
estar social, tema que extrapola os limites deste texto. De outro lado, ocorre um círculo vicioso: os municípios que registram menor PIB per capita são os que disponibilizam menor despesa pública per capita.

TABELA 1 - POPULAÇÃO, PRODUTO INTERNO BRUTO TOTAL E PER CAPITA DOS MUNICÍPIOS DA REGIÃO METROPOLITANA DE CURITIBA, 2008, 2009 E 2010

\begin{tabular}{|c|c|c|c|c|c|}
\hline \multirow{2}{*}{ MUNICÍPIOS } & \multicolumn{3}{|c|}{ POPULAÇÃO ${ }^{(1)}$} & \multicolumn{2}{|c|}{ PIB $^{(2)}$} \\
\hline & URBANA & RURAL & TOTAL & TOTAL & PER CAPITA \\
\hline Adrianópolis & 2.060 & 4.314 & 6.374 & $64.564,00$ & $9.624,00$ \\
\hline Agudos do Sul & 2.822 & 5.448 & 8.270 & $44.043,00$ & $5.376,00$ \\
\hline Almirante Tamandaré & 98.954 & 4.291 & 103.245 & $516.475,00$ & $5.550,00$ \\
\hline Araucária & 110.293 & 8.914 & 119.207 & $9.536 .015,00$ & $86.736,00$ \\
\hline Balsa Nova & 6.871 & 4.423 & 11.294 & $210.271,00$ & $19.764,00$ \\
\hline Bocaiúva do Sul & 5.136 & 5.869 & 11.005 & $70.830,00$ & $7.430,00$ \\
\hline Campina Grande do Sul & 31.937 & 6.819 & 38.756 & $314.735,00$ & $9.655,00$ \\
\hline Campo Largo & 94.253 & 18.233 & 112.486 & $1.295 .125,00$ & $12.277,00$ \\
\hline Campo Magro & 19.548 & 5.288 & 24.836 & $138.429,00$ & $6.201,00$ \\
\hline Cerro Azul & 4.814 & 12.134 & 16.948 & $141.581,00$ & $8.002,00$ \\
\hline Colombo & 203.251 & 9.776 & 213.027 & $1.513 .697,00$ & $6.471,00$ \\
\hline Contenda & 9.233 & 6.659 & 15.892 & $132.956,00$ & $8.894,00$ \\
\hline Curitiba & 1.746 .896 & 0 & 1.746 .896 & $37.791 .140,00$ & $21.025,00$ \\
\hline Doutor Ulysses & 939 & 4.795 & 5.734 & $67.320,00$ & $11.303,00$ \\
\hline Fazenda Rio Grande & 75.940 & 5.747 & 81.687 & $420.014,00$ & $5.600,00$ \\
\hline Itaperuçu & 19.966 & 3.933 & 23.899 & $121.515,00$ & $5.518,00$ \\
\hline Lapa & 27.228 & 17.708 & 44.936 & $569.354,00$ & $13.660,00$ \\
\hline Mandirituba & 7.419 & 14.816 & 22.235 & $179.785,00$ & $8.810,00$ \\
\hline Pinhais & 117.166 & 0 & 117.166 & $2.089 .739,00$ & $18.652,00$ \\
\hline Piraquara & 45.779 & 47.500 & 93.279 & $362.732,00$ & $4.423,00$ \\
\hline Quatro Barras & 17.923 & 1.863 & 19.786 & $383.911,00$ & $21.181,00$ \\
\hline Quitandinha & 4.886 & 12.202 & 17.088 & $92.369,00$ & $5.810,00$ \\
\hline Rio Branco do Sul & 22.044 & 8.618 & 30.662 & $454.791,00$ & $14.444,00$ \\
\hline São José dos Pinhais & 236.233 & 27.255 & 263.488 & $8.493 .381,00$ & $32.218,00$ \\
\hline Tijucas do Sul & 2.267 & 12.529 & 14.526 & $110.112,00$ & $8.411,00$ \\
\hline Tunas do Paraná & 2.790 & 3.468 & 6.258 & $47.409,00$ & $8.007,00$ \\
\hline TOTAL & 2.916 .648 & 252.648 & 3.168 .980 & - & \\
\hline
\end{tabular}

FONTE: (1) Censo Demográfico 2010 - IBGE.

(2) Produto Interno Bruto (PIB) 2007 in Cadernos Municipais - IPARDES.

TABELA 2 - FINANÇAS PÚBLICAS DOS MUNICÍPIOS DA REGIÃO METROPOLITANA DE CURITIBA, 2008, 2009 E 2010

\begin{tabular}{l|r|r|r|r|r}
\hline \multirow{2}{*}{ MUNICÍPIOS } & \multicolumn{3}{c|}{ RECEITA (R\$) $^{(3)}$} & \multicolumn{2}{c}{ DESPESA (RS) ${ }^{(4)}$} \\
\cline { 2 - 7 } & $\begin{array}{c}\text { ORÇAMEN- } \\
\text { TÁRIA }\end{array}$ & $\begin{array}{c}\text { TRANSFE- } \\
\text { RENCIAS } \\
\text { CORRENTES }\end{array}$ & PER CAPITA & $\begin{array}{c}\text { ORÇAMENTÁ- } \\
\text { RIA }\end{array}$ & PER CAPITA \\
\hline Adrianópolis & $11.165 .118,00$ & $10.061 .542,00$ & $1.751,67$ & $9.599 .694,00$ & $1.506,07$ \\
Agudos do Sul & $8.871 .244,00$ & $8.293 .038,00$ & $1.072,70$ & $9.278 .657,00$ & $1.121,97$ \\
Almirante Tamandaré & $66.250 .132,00$ & $50.934 .754,00$ & 641,98 & $56.172 .520,00$ & 544,07 \\
Araucária & $366.175 .594,00$ & $281.652 .073,00$ & $3.071,76$ & $315.829 .661,00$ & $2.649,42$ \\
Balsa Nova & $19.423 .010,00$ & $16.410 .405,00$ & $1.719,76$ & $18.063 .717,00$ & $1.599,41$ \\
Bocaiúva do Sul & $13.473 .435,00$ & $10.818 .729,00$ & $1.224,30$ & $13.340 .799,00$ & $1.212,25$ \\
Campina Grande do & $44.978 .907,00$ & $30.190 .138,00$ & $1.160,57$ & $39.891 .687,00$ & $1.029,30$ \\
Sul & $123.755 .313,00$ & $77.506 .255,00$ & $1.100,18$ & $108.390 .995,00$ & 963,60 \\
Campo Largo & $27.715 .885,00$ & $32.565 .740,00$ & $1.115,96$ & $24.954 .760,00$ & $1.004,78$ \\
Campo Magro & & & & & \\
\hline
\end{tabular}


TABELA 2 (CONTINUAÇÃO) - FINANÇAS PÚBLICAS DOS MUNICÍPIOS DA REGIÃO METROPOLITANA DE CURITIBA, 2008, 2009 E 2010

\begin{tabular}{|c|c|c|c|c|c|}
\hline \multirow[b]{2}{*}{ MUNICÍPIOS } & \multicolumn{3}{|c|}{ RECEITA $(\mathbf{R} \$)^{(3)}$} & \multicolumn{2}{|c|}{ DESPESA (RS) ${ }^{(4)}$} \\
\hline & $\begin{array}{c}\text { ORÇAMEN- } \\
\text { TÁRIA }\end{array}$ & $\begin{array}{c}\text { TRANSFE- } \\
\text { RÊNCIAS } \\
\text { CORRENTES }\end{array}$ & PER CAPITA & $\begin{array}{c}\text { ORÇAMENTÁ- } \\
\text { RIA }\end{array}$ & PER CAPITA \\
\hline Cerro Azul & $20.683 .757,00$ & $18.727 .801,00$ & $1.220,42$ & $19.844 .352,00$ & $1.170,90$ \\
\hline Colombo & 244.936.929,00 & $118.163 .498,00$ & $1.149,79$ & $162.130 .506,00$ & 761,08 \\
\hline Contenda & $18.822 .558,00$ & 1.339.214,00 & $1.146,49$ & $17.089 .029,00$ & $1.075,32$ \\
\hline Curitiba & 4.049.326.763,00 & $1.394 .411 .450,00$ & $2.318,01$ & 3.971.212.409,00 & $2.273,30$ \\
\hline Doutor Ulysses & $\mathrm{NC}$ & $\mathrm{NC}$ & $\mathrm{NC}$ & $\mathrm{NC}$ & $\mathrm{NC}$ \\
\hline Fazenda Rio Grande & $66.940 .588,00$ & $46.288 .859,00$ & 819,48 & $62.742 .684,00$ & 768,09 \\
\hline Itaperuçu & $18.822 .558,00$ & $17.253 .470,00$ & 787,59 & $17.681 .334,00$ & 739,94 \\
\hline Lapa & $54.961 .456,00$ & $38.230 .632,00$ & $1.223,11$ & $51.791 .476,00$ & $1.152,56$ \\
\hline Mandirituba & $25.396 .966,00$ & $21.055 .085,00$ & $1.142,21$ & $25.271 .741,00$ & $1.136,57$ \\
\hline Pinhais & $138.940 .671,00$ & $86.632 .463,00$ & $1.185,54$ & $140.842 .211,00$ & $1.202,07$ \\
\hline Piraquara & $76.472 .635,00$ & $61.128 .910,00$ & 819,83 & $77.552 .000,00$ & 831,40 \\
\hline Quatro Barras & $42.309 .048,00$ & $21.640 .358,00$ & $2.138,33$ & $32.486 .439,00$ & $1.641,89$ \\
\hline Quitandinha & $17.700 .675,00$ & $14.774 .267,00$ & $1.035,85$ & $16.946 .866,00$ & 991,57 \\
\hline Rio Branco do Sul & $34.512 .900,00$ & $30.376 .078,00$ & $1.125,59$ & $43.051 .295,00$ & $1.404,06$ \\
\hline São José dos Pinhais & $410.271 .746,00$ & $273.090 .351,00$ & $1.557,08$ & $361.676 .977,00$ & $1.372,65$ \\
\hline Tijucas do Sul & $18.060 .219,00$ & $15.849 .524,00$ & $1.243,30$ & $16.752 .998,00$ & $1.153,31$ \\
\hline Tunas do Paraná & $10.546 .744,00$ & $9.464 .153,00$ & $1.685,32$ & 10.141.099,00 & $1.620,50$ \\
\hline TOTAL & - & - & - & - & \\
\hline
\end{tabular}

FONTE: (3) Finanças Públicas 2009 in Cadernos Municipais - IPARDES.

(4) Finanças Públicas 2009 in Cadernos Municipais - IPARDES.

\section{CONCLUSÃO}

Não há no horizonte perspectivas de inverter as tendências concentradoras observadas. Isto pode significar que continuarão os processos de esvaziamento e segregação da população metropolitana a partir dos municípios mais frágeis. Esta tendência poderá ser reforçada pela constituição de áreas “fechadas” para a população de média e alta renda, mediadas pela disponibilidade de infraestrutura de transportes e serviços. As assimetrias observadas e o excessivo peso polarizador de Curitiba reforçam a importância de refletir a respeito das peças que faltam na nossa Federação para enfrentar, com planejamento e poder fiscal e financeiro, os impiedosos processos de urbanização do Brasil e da Região Metropolitana de Curitiba. 


\section{REFERÊNCIAS}

INSTITUTO BRASILEIRO DE GEOGRAFIA E ESTATÍSTICA. Censo Demográfico 2010. Rio de Janeiro, 2010.

INSTITUTO PARANAENSE DE DESENVOLVIMENTO ECONÔMICO E SOCIAL Cadernos Municipais. Curitiba, 2010.

INSTITUTO DE PLANEJAMENTO ECONÔMICO APLICADO. Fundação João Pinheiro, Programa das Nações Unidas para o Desenvolvimento (PNUD). Índice de Desenvolvimento Humano Municipal (IDH-M). Belo Horizonte, 2003. 